Journal of Advanced Research in Fluid Mechanics and Thermal Sciences

Journal homepage: www.akademiabaru.com/arfmts.html ISSN: 2289-7879

\title{
Transition Between Constitutive Equations and the Mechanics of Water Flow in Unsaturated Soil: Numerical Simulations
}

\author{
Sunny Goh Eng Giap ${ }^{1,}{ }^{*}$, Noborio Kosuke ${ }^{2}$ \\ Faculty of Ocean Engineering Technology and Informatics, Universiti Malaysia Terengganu, 21030 Kuala Terengganu, Terengganu, Malaysia \\ Meiji University, 1-1-1 Higashimita, Tama-ku, Kawasaki 214-8571, Japan
}

\section{ARTICLE INFO ABSTRACT}

Article history:

Received 4 September 2020

Received in revised form 30 October 2020

Accepted 31 October 2020

Available online 11 January 2021

Keywords:

Water flow in soil; unsaturated soil; water flux; water adsorption

\begin{abstract}
Richards' partial differential equation normally governs water flows in soil. It can be utilized to investigate water infiltration in the soil. A case study of the Haverkamp's water infiltration simulation into Yolo Light Clay was carried out. A common practice to change between the hydraulic functions (from Haverkamp to van Genuchten) could cause a discrepancy in the simulation results. Hence, the first objective is to modify van Genuchten's equations to reproduce the water infiltration result that was obtained using the Haverkamp constitutive functions. The method used was able to recreate water infiltration by increasing the fitting parameters of the van Genuchten constitutive functions. The second objective is to identify the mechanism governing the flow of water. The soil water diffusivity and the hydraulic conductivity were responsible for the flux of water in the soil. The Richards' equation was discretized using a finite difference method, and the algebraic solution was coded into Simply Fortran 2008.
\end{abstract}

\section{Introduction}

Richards' equation consists of a governing equation that is used to describe the water flow in subsurface porous media such as soil in unsaturated conditions [1]. It is continuously subjected to numerical investigation [2-11]. The modeling of water distribution using the equation has essential applications in climate science, agriculture and also ecosystem management [12]. Among many applications, Zeide [13] has reported the use of Richards' equation in the tree growth modelling prediction. Soil scientists, agronomists, and irrigation engineers have found the equation useful to relate to plant water uptake, and fertilizers and pesticides advection and dispersion in the soils [14]. In addition, other equation like Navier-Stokes could be used to investigate flow in porous media, but the flow investigation would be more complicated $[15,16]$.

\footnotetext{
* Corresponding author.

E-mail address: sunnygoh@gmail.com
}

https://doi.org/10.37934/arfmts.79.2.110 
A nonlinear partial differential equation represents the governing equation. It is often difficult to approximate because it does not have a closed-form analytical solution [17]. Richards' equation consists of two parts; the water flux expression that is similar to Darcy's law, and the continuity equation is used to monitor the mass balance of water flux in and out of a control volume. The equation to describe the unsaturated flow can be written in three forms, as follows

Head-based, $C\left(\psi_{m}\right) \frac{\partial \psi_{m}}{\partial t}=\frac{\partial}{\partial z}\left(K \frac{\partial \psi_{m}}{\partial z}\right)-\frac{\partial K}{\partial z}$

Mixed-based, $\frac{\partial \theta_{L}}{\partial t}=\frac{\partial}{\partial z}\left(K \frac{\partial \psi_{m}}{\partial z}\right)-\frac{\partial K}{\partial z}$

Saturation-based, $\frac{\partial \theta_{L}}{\partial t}=\frac{\partial}{\partial z}\left(D\left(\theta_{L}\right) \frac{\partial \theta_{L}}{\partial z}\right)-\frac{\partial K}{\partial z}$

where the detailed description on Eq. (1) was described in Rathfelder and Abriola [18]. Similarly, Kavetski et al., [19] and Zeng and Decker [20] have provided a detailed explanation for mixed- and saturation-based of Richards' equation. To implement the equation, the soil water retention relation $\left(\theta_{L}\right.$ as a function of $\psi_{m}$ ) and the unsaturated hydraulic conductivity relation ( $K$ as a function of $\psi_{m}$ ) must be known from measurement [21].

Water infiltration is one of the common applications for Richards' equation, and the water infiltrated medium is normally assumed as homogeneous and isotropic [22]. In reality, the water flux regime could be affected depending on the locations in the soil that could be resulted from different transport coefficients such as the soil water retention curve and hydraulic conductivity relations, including, a spatial variation of different saturated volumetric water contents [23]. There are different constitutive functions to describe the water retention curve and hydraulic conductivity relation, for example, van Genuchten [24], Campbell [25], and Haverkamp et al., [26]. The experimental dataset described by a constitutive function used in Richards' equation will affect the water infiltration profile.

Different water infiltration profiles resulting from different constitutive functions are a wellknown problem, but there are still no published records on a solution. This problem is commonplace when one is applying published coefficients of a particular water retention curve equation, for example, Haverkamp [26], to conduct simulation study, and then, attempt to change between constitutive function equations, for example, from Haverkamp et al., [26] to van Genuchten [24] equation. One would have to recreate the dataset using Haverkamp equation coefficients first and then, redo the curve-fitting on the dataset using the Genuchten equation, hence, resulting in different water infiltration profiles. Therefore, the first objective of the study is to provide a solution for the transition between constitutive equations and be able to produce similar water infiltration profile.

Richards' equation, as described by Hopmans [21], is a mass conservation equation and includes the expression of Darcy's law. An in-depth description of Richards' equation is also given by Germann [27] from the perspective of the Navier-Stokes equation. However, taking the case of water infiltration as an example, the influence of the coefficients $\left(D\left(\psi_{m}\right), K, \theta_{L}-\psi_{m}\right)$ as in Eq. (3) on water infiltration profile have not been discussed prior. The second objective of this study is to reveal the mechanics behind Richards' equation as governed by the coefficients. 


\section{Methodology}

Richards' equation was reported as not behaving as mass conserving equation when using Eq. (1) [28]. Eq. (2) and (3) were free from the mass conservation problem. The water-based Richards' equation in Eq. (3) was chosen and used in this study because the volumetric water content appeared in the independent and dependent variables which would ease the programming effort. The $D\left(\psi_{m}\right)$ is the soil water diffusivity $\left(\mathrm{m}^{2} \cdot \mathrm{s}^{-1}\right)$, and it is given by

$D\left(\psi_{m}\right)=K\left(\psi_{m}\right) \frac{\partial \psi_{m}}{\partial \theta_{L}}$

where $\frac{\partial \psi_{m}}{\partial \theta_{L}}$ is the derivative of matric suction $\left(\psi_{m},-\mathrm{m}\right)$ with respect to volumetric water content ( $\left.\theta_{L}, \mathrm{~m}^{3} \cdot \mathrm{m}^{-3}\right)$, and $K\left(\psi_{m}\right)$ is the hydraulic conductivity $\left(\mathrm{m} \cdot \mathrm{s}^{-1}\right)$ of the soil.

The constitutive functions from Haverkamp et al., [26] for the water retention curve $\left(\theta_{L}-\psi_{m}\right)$ and hydraulic conductivity $\left(K\left(\psi_{m}\right)\right)$ are given by

$$
\begin{aligned}
& \psi_{m}=-10^{-2} \exp \left[\frac{\alpha\left(\theta_{s}-\theta_{r}\right)}{\theta_{L}-\theta_{r}}-\alpha\right]^{1 / \beta} \\
& K=K_{s} \frac{A}{A+\left(\exp \left[\frac{\alpha\left(\theta_{s}-\theta_{r}\right)}{\theta_{L}-\theta_{r}}-\alpha\right]^{1 / \beta}\right)^{B}}
\end{aligned}
$$

van Genuchten's [24] water retention curve and hydraulic functions are given below

$$
\begin{aligned}
& \psi_{m}=-\frac{1}{\alpha_{1}}\left[\left(\frac{\theta_{s}-\theta_{r}}{\theta_{L}-\theta_{r}}\right)^{1 / m}-1\right]^{1 / n} \\
& K=K_{s}\left(\frac{\theta_{L}-\theta_{r}}{\theta_{s}-\theta_{r}}\right)^{L}\left\{1-\left[1-\left(\frac{\theta_{L}-\theta_{r}}{\theta_{s}-\theta_{r}}\right)^{1 / m}\right]^{m}\right\}^{2}
\end{aligned}
$$

where $\alpha, \alpha_{1}, A, B, \beta, L$ and $n$ are fitting parameters, $\theta_{s}$ is saturated water content $\left(\mathrm{m}^{3} \cdot \mathrm{m}^{-3}\right), \theta_{r}$ is residual water content $\left(\mathrm{m}^{3} \cdot \mathrm{m}^{-3}\right), K_{s}$ is saturated hydraulic conductivity $\left(\mathrm{m} \cdot \mathrm{s}^{-1}\right)$, and $m$ is also fitting parameter where $m=1-1 / n$.

In order to implement Richards' equation, Eq. (3) was discretized into algebraic equations using the cell-centered finite-difference method, as follows, 


$$
\begin{gathered}
\frac{\theta_{L(k)}{ }^{n+1}-\theta_{L(k)}{ }^{n}}{\Delta t}=\frac{K_{k+1 / 2}\left(\partial \psi_{m} / \partial \theta_{L}\right)_{k+1 / 2}}{(\Delta z)^{2}}\left(\theta_{L(k+1)}{ }^{n+1}-\theta_{L(k)}{ }^{n+1}\right) \\
-\frac{K_{k-1 / 2}\left(\partial \psi_{m} / \partial \theta_{L}\right)_{k-1 / 2}}{(\Delta z)^{2}}\left(\theta_{L(k)}{ }^{n+1}-\theta_{L(k-1)}{ }^{n+1}\right) \\
-\frac{K_{k+1 / 2} \vec{k}-K_{k-1 / 2} \vec{k}}{\Delta z}
\end{gathered}
$$

where $k$ indicates a centre cell in the $z$-direction of a cartesian coordinate system, $+1 / 2$ refers to the interface of cell located between the cell $k$ and $k+1,-1 / 2$ refers to cell interface between the cells $k-1$ and $k, n$ indicates the current time, $n+1$ indicates new time, and $\Delta$ refers to the difference of a parameter. Eq. (9) is oriented positive downward, as does Eq. (3). A complete description of the numerical scheme was explained in Goh and Noborio [29]. The equations were coded in Fortran.

Water infiltration phenomenon was used as a case study. The soil type used was Yolo light clay. A schematic diagram as in Figure 1 provides a simplistic view of the model environment.

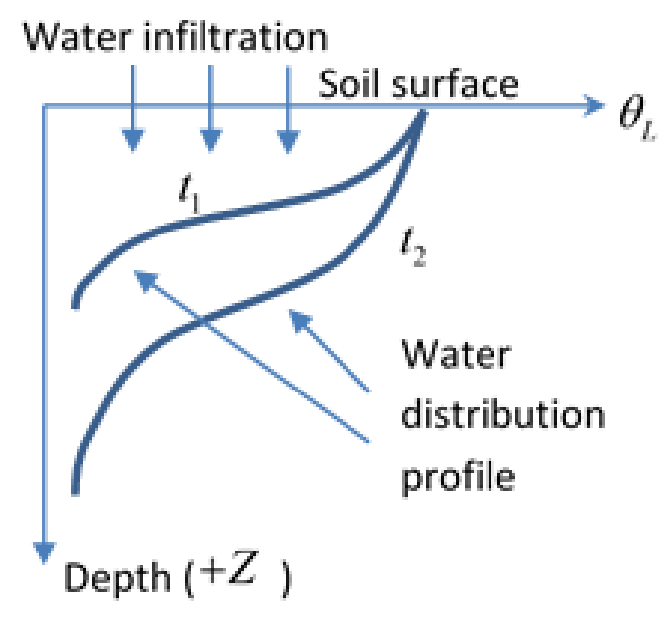

Fig. 1. Water distribution in the soil by a schematic diagram for soil water infiltration profile

\section{Results}

\subsection{Validation of Simulation Results with Philip's Semianalytical Solution}

The Yolo light clay soil was initially wet with a homogeneous soil moisture content of $0.2376 \mathrm{~m}^{3}$. $\mathrm{m}^{-3}$. The clay properties are shown in Table 1 . The water infiltration begins with the upper soil body saturated with $0.495 \mathrm{~m}^{3} \cdot \mathrm{m}^{-3}$ soil moisture content, and the lower soil body was assumed permeable to water, that is to say, water is free to move in and out. The total soil depth was taken as $2.5 \mathrm{~m}$. The soil depth was further divided into 100 cells, where each cell represents $2.5 \mathrm{~cm}$. Each cell was governed by Eq. (9), and the cells were simulated simultaneously in Fortran.

To make sure Richards' equation was programmed correctly, the simulation has to be validated either by experimentation or an analytical solution dataset. In this case study, we used Philip's semianalytical solution [30-32] to validate the Fortran code. The results are shown in Figure 2 . The 
R-squared showed a good match between Fortran simulation and the analytical solution of water infiltration profiles at $1.16,11.6$ and 34.7 days that were $0.9992,0.9988$ and 0.9994 , respectively.

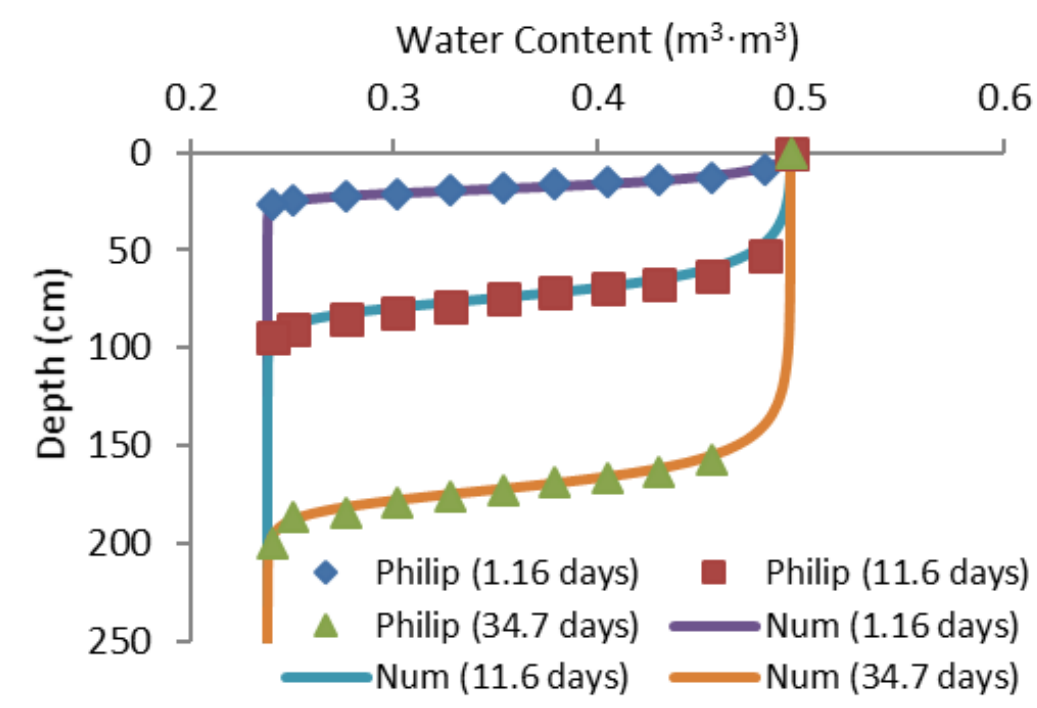

Fig. 2. Water distribution in the soil by water infiltration profile in Yolo light clay after 1.16, 11.6 and 34.7 days. Philip and Num referred to Philip's semianalytical solution and the Fortran coded numerical simulation, respectively

Table 1

The soil type is Yolo light clay. The parameters used were retrieved from Haverkamp et al., [26] Parameters

\begin{tabular}{lllllll}
$\alpha$ & $\theta_{r}\left(\mathrm{~m}^{3} \cdot \mathrm{m}^{-3}\right)$ & $\theta_{s}\left(\mathrm{~m}^{3} \cdot \mathrm{m}^{-3}\right)$ & $\beta$ & $A$ & $B$ & $K_{s}\left(\mathrm{~m} \cdot \mathrm{s}^{-1}\right)$ \\
\hline 739 & 0.124 & 0.495 & 4 & 124.6 & 1.77 & $1.23 \times 10^{-7}$ \\
\hline
\end{tabular}

Note: $\alpha, A, B$ and $\beta$ are fitting parameters, $\theta_{s}$ is saturated water content, $\theta_{r}$ is residual water content, and $K_{s}$ is saturated hydraulic conductivity

\subsection{The Problem of Transition Between Constitutive Equations}

Water retention curve is also known as a water characteristic curve. There are many water characteristic curve equation [33], and a new equation is continuously being proposed [34]. Hence, it would be impossible to address all the transition issues between all the equations. However, a simple case study would be discussed here as an example to demonstrate the technique used, which can be referred to as a transition method in solving similar problems.

Changing the characteristic curve equation, for example from Haverkamp to van Genuchten equations, with the same dataset could result in different water infiltration profile, as shown in Figure 4(a). This is because fitting Haverkamp's and van Genuchten's equations on the same dataset produced different curves for the relationship between soil water content and soil matric suction, and also resulted in the different curves between the hydraulic conductivity and water saturation. Figure $3(\mathrm{a})$ shows the modified van Genuchten (R-squared $=0.899$ ) is closer to the soil water content data than the original version of van Genuchten (R-squared $=0.894)$. Similarly, in Figure 3(b), the modified van Genuchten ( $R$-squared $=0.999$ ) resulted in better hydraulic conductivity that is closely approximate the data than the unmodified van Genuchten ( $\mathrm{R}$-squared $=0.919$ ). 
As shown in Figure 4(a), at 34.7 days, the original van Genuchten equation simulation had under predicted the water infiltration profile. In achieving objective one that is to have equal water infiltration profiles that transition from Haverkamp's to van Genuchten's equations, the classical van Genuchten - Mualem formulas in Eq. (7) and (8) were modified. Their modification that is modified van Genuchten, with appropriate parameters $m_{1}, n_{1}, m_{2}$, and $n_{2}$, in Eq. (10) and (11).

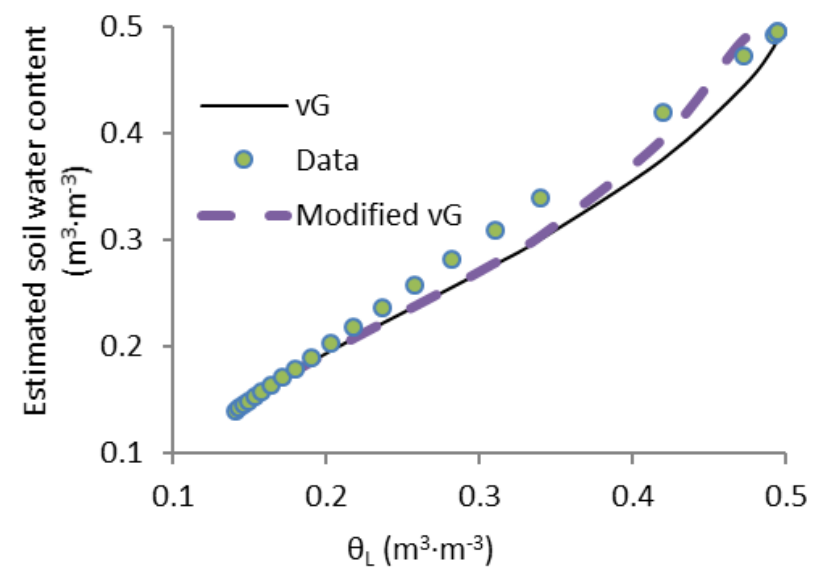

(a)

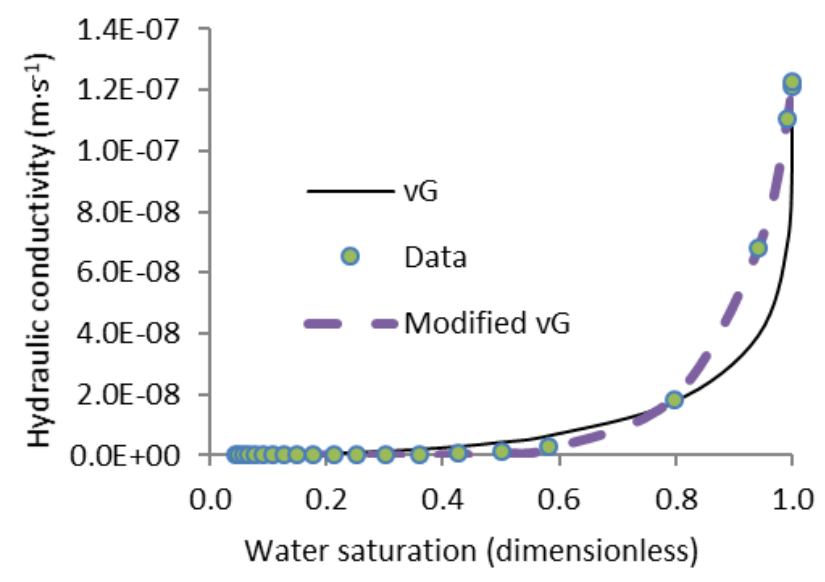

(b)

Fig. 3. The curve-fitted results of modified van Genuchten (as Modified vG), original van Genuchten (as vG) and data for (a) soil water content, and (b) hydraulic conductivity

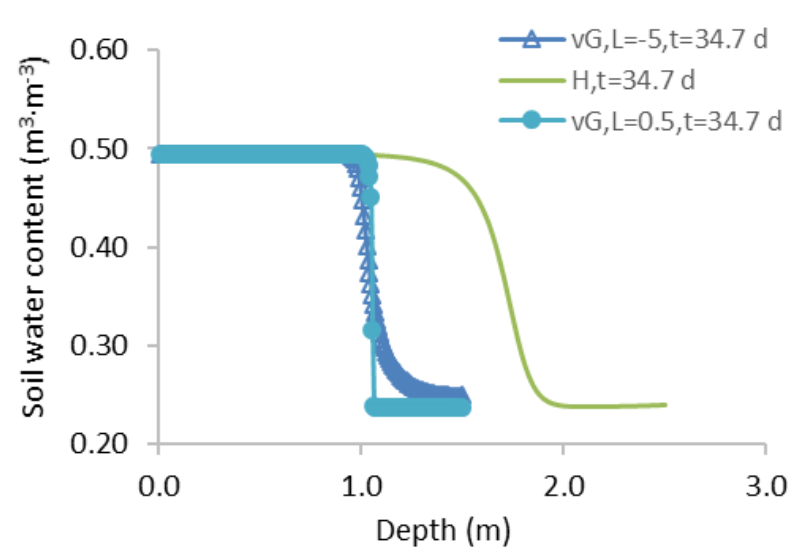

(a)

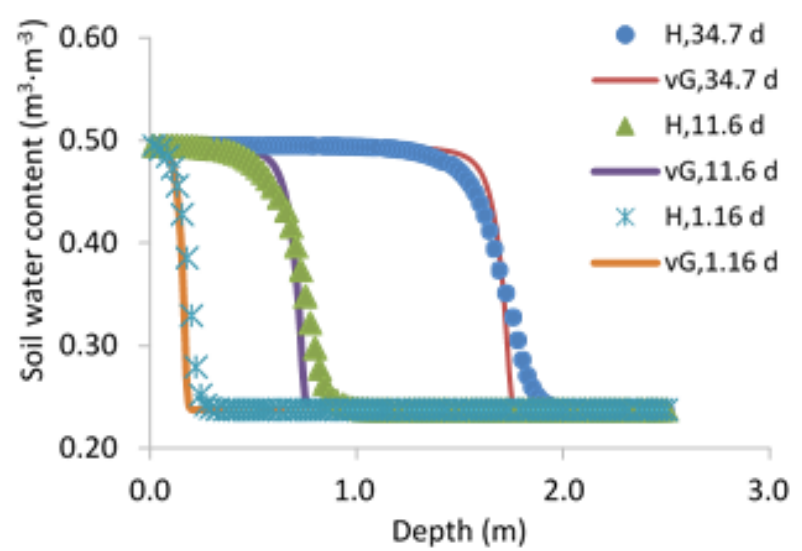

(b)

Fig. 4. Water infiltration profile for Genuchten's and Haverkamp's equations simulated at: (a) 34.7 days with $m, n, \alpha_{1}$ curve-fitted, while $L$ fixed at 0.5 or -5 for original van Genuchten; and (b) 1.16, 11.6, 34.7 days with $L, m_{1}, n_{1}, m_{2}, n_{2}, \alpha_{1}$ curve-fitted for modified van Genuchten. Note: vG and $\mathrm{H}$ corresponding to Genuchten and Haverkamp

$\psi_{m}=-\frac{1}{\alpha_{1}}\left[\left(\frac{\theta_{s}-\theta_{r}}{\theta_{L}-\theta_{r}}\right)^{1 / m_{1}}-1\right]^{1 / n_{1}}$
$K=K_{s}\left(\frac{\theta_{L}-\theta_{r}}{\theta_{s}-\theta_{r}}\right)^{L}\left\{1-\left[1-\left(\frac{\theta_{L}-\theta_{r}}{\theta_{s}-\theta_{r}}\right)^{1 / n_{2}}\right]^{m_{2}}\right\}^{2}$ 
The curve-fitting parameters were increased from 3 to 6 . The intention of the modification was to increase the ability of the Eq. (10) and (11) to have a better curve-fitting ability than Eq. (7) and (8). Figure 4(b) has proven the effectiveness of this method which was able to recreate the centre of the water infiltration front, possible beyond 34.7 days.

Therefore, the best practice is to make the equation parameters unbound between the characteristic curve equation (Eq. (10)) and the hydraulic conductivity equation (Eq. (11)). This practice can be applied to other studies without much difficulty.

\subsection{The Mechanics of Richards' Equation}

Figure 4(b) showed that Richards' equation, using the improved Genuchten Eq. (10) and (11) has significantly improved the simulation to match with those of Haverkamp. The water infiltration front appeared sharply from 34.7 to 1.16 days of simulation. Although the improved Genuchten's equation is able to reproduce the water-front centre, it reproduces a sharper water front than that of Haverkamp's. The Genuchten water-front appeared to increase in the high water content spatial region sharply and sharply decreased at the low water content spatial region. This occurrence can be explained by the relationship between hydraulic conductivity $(K)$ and soil moisture content, as in Figure 5(a), where the Genuchten curve gives a higher hydraulic conductivity at the high water content region and a lower hydraulic conductivity at the low water content region. Figure 5(b) shows the rarely reported relation between $\frac{\partial \psi_{m}}{\partial \theta_{L}}$ and the soil moisture content. The graph shows a concave curve with a minimum which reached at $0.4586 \mathrm{~m}^{3} \cdot \mathrm{m}^{-3}$, which indicates a minimum gradient. Knowing that $D\left(\theta_{L}\right)$ in Eq. (4) consist of $K\left(\theta_{L}\right)$ and $\frac{\partial \psi_{m}}{\partial \theta_{L}}$, the former variable is always high at high soil moisture content as in Figure 5(a), whereas the latter variable would have to depend on the region soil wetness. This means that $\left(\partial \psi_{m} / \partial \theta_{L}\right)_{k-1 / 2}-\left(\partial \psi_{m} / \partial \theta_{L}\right)_{k+1 / 2}$ in space may not always be positive in value because it depends on the level of soil wetness. Whereas the $D\left(\theta_{L}\right)_{k-1 / 2}-D\left(\theta_{L}\right)_{k+1 / 2}$ is always positive for water infiltration front as long as the water is continuously infiltrating into the soil, which explains the increasing soil water content with time in the soil depth.

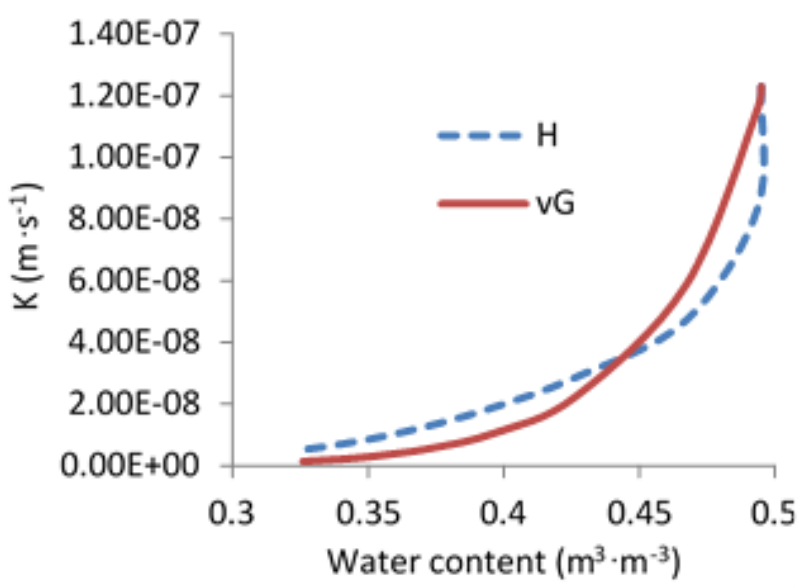

(a)

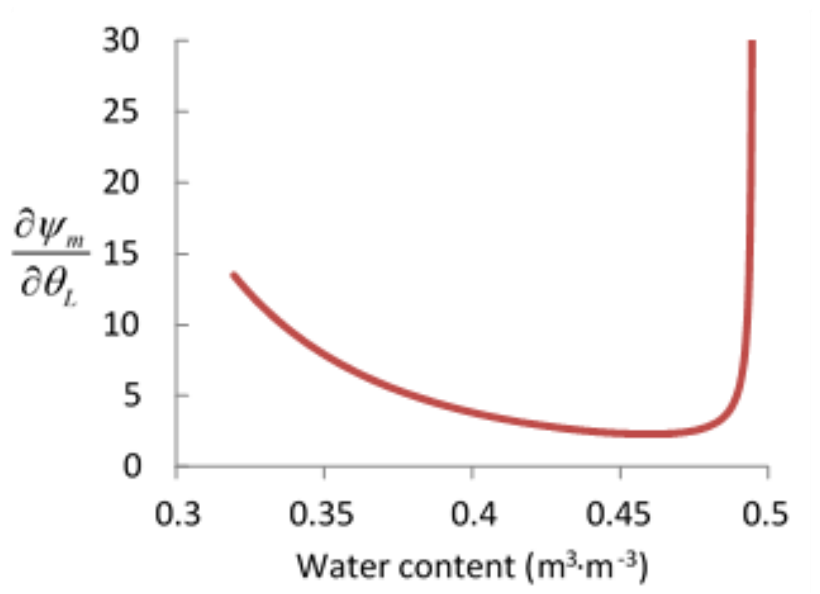

(b)

Fig. 5. (a) Hydraulic conductivity varies with soil moisture content, and (b) the derivative of soil matric suction with respect to moisture content varies with soil moisture content 


\section{Conclusions}

Richards' equation is important to govern water flow in the unsaturated soil, which acts as an interface between the atmosphere and the groundwater. Richards' equation which is frequently used in conjunction with other constitutive equations (water characteristic curve and hydraulic functions), does not allow easy transition between equations, for example from Haverkamp's to Genuchten's. In the first objective, we have demonstrated that a simple modification of the existing Genuchten variables was able to reproduce the water infiltration front. In the second objective, we have discussed the importance of understanding the variables in Richards' equation in order to be able to understand the mechanics of water transport and also to be able to describe the observed sharp water infiltration front produced from using Genuchten's equation. The hidden property of the derivative of soil matric suction, with respect to the soil moisture content, is often overlooked but it has influenced the influx of water into the soil.

\section{Acknowledgement}

This research was supported by Ministry of Higher Education (MOHE) through Fundamental Research Grants Scheme FRGS/1/2020/STG08/UMT/02/2.

\section{References}

[1] Richards, L. A. "Soil-water conduction of liquids in porous mediums." Physics 1 (1931): 318-333. https://doi.org/10.1063/1.1745010

[2] Ngo-Cong, Duc, Nam Mai-Duy, Diogenes L. Antille, and Martinus Th van Genuchten. "A control volume scheme using compact integrated radial basis function stencils for solving the Richards equation." Journal of Hydrology 580 (2020): 124240. https://doi.org/10.1016/j.jhydrol.2019.124240

[3] Berardi, Marco, Fabio Difonzo, and Luciano Lopez. "A mixed MoL-TMoL for the numerical solution of the 2D Richards' equation in layered soils." Computers \& Mathematics with Applications 79, no. 7 (2020): 1990-2001. https://doi.org/10.1016/j.camwa.2019.07.026

[4] Fengnan, Liu, Yasuhide Fukumoto, and Xiaopeng Zhao. "A linearized finite difference scheme for the Richards equation under variable-flux boundary conditions." Journal of Scientific Computing 83, no. 1 (2020): 16. https://doi.org/10.1007/s10915-020-01196-y

[5] Batista, Juan, Xiaozhe Hu, and Ludmil T. Zikatanov. "Auxiliary space preconditioning for mixed finite element discretizations of Richards' equation." Computers \& Mathematics with Applications 80, no. 2 (2020): 405-416. https://doi.org/10.1016/i.camwa.2019.09.011

[6] De Rango, Alessio, Luca Furnari, Andrea Giordano, Alfonso Senatore, Donato D'Ambrosio, William Spataro, Salvatore Straface, and Giuseppe Mendicino. "OpenCAL system extension and application to the three-dimensional Richards equation for unsaturated flow." Computers \& Mathematics with Applications (2020). https://doi.org/10.1016/i.camwa.2020.05.017

[7] Armiti-Juber, Alaa, and Christian Rohde. "On the well-posedness of a nonlinear fourth-order extension of Richards' equation." Journal of Mathematical Analysis and Applications (2020): 124005. https://doi.org/10.1016/j.jmaa.2020.124005

[8] Bassetto, Sabrina, Clément Cancès, Guillaume Enchéry, and Quang Huy Tran. "Robust Newton solver based on variable switch for a finite volume discretization of Richards equation." In International Conference on Finite Volumes for Complex Applications, pp. 385-393. Springer, Cham, 2020.

https://doi.org/10.1007/978-3-030-43651-3 35

[9] Gąsiorowski, Dariusz, and Tomasz Kolerski. "Numerical Solution of the Two-Dimensional Richards Equation Using Alternate Splitting Methods for Dimensional Decomposition." Water 12, no. 6 (2020): 1780. https://doi.org/10.3390/w12061780

[10] Liu, Fengnan, Yasuhide Fukumoto, and Xiaopeng Zhao. "Stability Analysis of the Explicit Difference Scheme for Richards Equation." Entropy 22, no. 3 (2020): 352.

https://doi.org/10.3390/e22030352 
[11] Chernogorova, Tatiana P., Miglena N. Koleva, and Lubin G. Vulkov. "Exponential finite difference scheme for transport equations with discontinuous coefficients in porous media." Applied Mathematics and Computation 392: 125691.

https://doi.org/10.1016/i.amc.2020.125691

[12] Daly, Edorado, and Amilcare Porporato. "A review of soil moisture dynamics: from rainfall infiltration to ecosystem response." Environmental engineering science 22, no. 1 (2005): 9-24. https://doi.org/10.1089/ees.2005.22.9

[13] SE, Jørgensen. "Ecological engineering: Overview. U: Encyclopedia of Ecology (SE Jørgensen, BD Fath, ur.)." (2008): 1024-1027. https://doi.org/10.1016/B978-008045405-4.00042-2

[14] Taigbenu, Akpofure E. "Unsaturated Flow (Richards Equation)." In The Green Element Method, pp. $217-230$. Springer, Boston, MA, 1999. https://doi.org/10.1007/978-1-4757-6738-4 8

[15] Fitriadhy, Ahmad, Nur Amira Adam, Nurul Aqilah Mansor, Mohammad Fadhli Ahmad, Ahmad Jusoh, Noraieni Hj. Mokhtar, and Mohd Sofiyan Sulaiman. "CFD Investigation into The Effect of Heave Plate on Vertical Motion Responses of a Floating Jetty." CFD Letters 12, no. 5 (2020): 24-35. https://doi.org/10.37934/cfdl.12.5.2435.

[16] Fohimi, Nor Azirah Mohd, Muhammad Hanif Asror, Rosniza Rabilah, Mohd Mahadzir Mohammud, Mohd Fauzi Ismail, and Farid Nasir Ani. "CFD Simulation on Ventilation of an Indoor Atrium Space." CFD Letters 12, no. 5 (2020): 52-59. https://doi.org/10.37934/cfdl.12.5.5259.

[17] Hillel, Daniel. Environmental soil physics: Fundamentals, applications, and environmental considerations. Elsevier, 1998.

[18] Rathfelder, Klaus, and Linda M. Abriola. "Mass conservative numerical solutions of the head-based Richards equation." Water Resources Research 30, no. 9 (1994): 2579-2586. https://doi.org/10.1029/94WR01302

[19] D. Kavetski, P. Binning, and S. W. Sloan. "Adaptive time stepping and error control in a mass conservative numerical solution of the mixed form of Richards equation." Advances in Water Resources 24, no. 6 (2001): 595-605. https://doi.org/10.1016/S0309-1708(00)00076-2

[20] Zeng, Xubin, and Mark Decker. "Improving the numerical solution of soil moisture-based Richards equation for land models with a deep or shallow water table." Journal of Hydrometeorology 10, no. 1 (2009): 308-319. https://doi.org/10.1175/2008JHM1011.1

[21] Hopmans, J. W. "Infiltration and Unsaturated Zone." (2011): 103-114. https://doi.org/10.1016/B978-0-444-53199-5.00031-2

[22] Hillel, Daniel, and Jerry L. Hatfield, eds. Encyclopedia of Soils in the Environment. Vol. 3. Amsterdam: Elsevier, 2005

[23] Sposito, G. "Physical Properties and Processes: Scaling." (2016). https://doi.org/10.1016/B978-0-12-409548-9.09696-2

[24] Van Genuchten, M. Th. "A closed-form equation for predicting the hydraulic conductivity of unsaturated soils." Soil science society of America journal 44, no. 5 (1980): 892-898. https://doi.org/10.2136/sssaj1980.03615995004400050002x

[25] Campbell, Gaylon S. "A simple method for determining unsaturated conductivity from moisture retention data." Soil science 117, no. 6 (1974): 311-314. https://doi.org/10.1097/00010694-197406000-00001

[26] Haverkamp, Roland, Michel Vauclin, Jaoudat Touma, P. J. Wierenga, and Georges Vachaud. "A comparison of numerical simulation models for one-dimensional infiltration." Soil Science Society of America Journal 41, no. 2 (1977): 285-294. https://doi.org/10.2136/sssaj1977.03615995004100020024x

[27] Germann, P. F. "Macropores and macropore flow, kinematic wave approach." (2005): 393-402. https://doi.org/10.1016/B0-12-348530-4/00491-4

[28] Celia, Michael A., Efthimios T. Bouloutas, and Rebecca L. Zarba. "A general mass-conservative numerical solution for the unsaturated flow equation." Water resources research 26, no. 7 (1990): 1483-1496. https://doi.org/10.1029/WR026i007p01483

[29] Goh, Eng Giap, and Kosuke Noborio. "Sensitivity analysis and validation for numerical simulation of water infiltration into unsaturated soil." International scholarly research notices 2015 (2015). https://doi.org/10.1155/2015/824721

[30] Philip, J. R. "The theory of infiltration: 1. The infiltration equation and its solution." Soil science 83, no. 5 (1957): 345-358. 
https://doi.org/10.1097/00010694-195705000-00002

[31] Philip, J. R. "Numerical solution of equations of the diffusion type with diffusivity concentrationdependent." Transactions of the faraday society 51 (1955): 885-892. https://doi.org/10.1039/tf9555100885

[32] Philip, J. Re. "Theory of infiltration." In Advances in hydroscience, vol. 5, pp. 215-296. Elsevier, 1969. https://doi.org/10.1016/B978-1-4831-9936-8.50010-6

[33] Haghverdi, Amir, Mohsen Najarchi, Hasan Sabri Öztürk, and Wolfgang Durner. "Studying Unimodal, Bimodal, PDI and Bimodal-PDI Variants of Multiple Soil Water Retention Models: I. Direct Model Fit Using the Extended Evaporation and Dewpoint Methods." Water 12, no. 3 (2020): 900. https://doi.org/10.3390/w12030900

[34] Zhang, Yuwei, Zhanping Song, Xiaolin Weng, and Yongli Xie. "A new soil-water characteristic curve model for unsaturated loess based on wetting-induced pore deformation." Geofluids 2019 (2019). https://doi.org/10.1155/2019/1672418 